Original Article

\title{
Is autonomic nervous system involved in restless legs syndrome during wakefulness?
}

\author{
Francesca Izzi a , Fabio Placidi a, Andrea Romigi a , Benedetta Lauretti ${ }^{\text {b }}$, Girolama A. Marfia ${ }^{\text {b }}$, \\ Nicola B. Mercuri a , Maria G. Marciani ${ }^{\text {b}}$, Camilla Rocchi ${ }^{\text {b,* }}$ \\ a Neurophysiopathology Unit, Sleep Medicine Center, Department of Systems Medicine, University of Rome "Tor Vergata”, Viale Oxford 81, 00133 Rome, Italy \\ ${ }^{\mathrm{b}}$ Neurology Unit, Department of Systems Medicine, University of Rome “Tor Vergata”, Viale Oxford 81, 00133 Rome, Italy
}

\section{A R T I C L E I N F O}

\section{Article history:}

Received 6 February 2014

Received in revised form 27 June 2014

Accepted 30 June 2014

Available online 22 August 2014

\section{Keywords:}

Restless legs syndrome

Heart rate variability

Cardiovascular reflexes

Autonomic nervous system

Sleep

Periodic limb movements

\begin{abstract}
A B S T R A C T
Objective: To investigate cardiovascular autonomic function in patients with restless leg syndrome (RLS) by means of cardiovascular reflexes and heart rate variability (HRV) during wakefulness.

Methods: Twelve RLS patients and 14 controls underwent cardiovascular function tests including headup tilt test (HUTT), Valsalva maneuver, deep breathing, hand grip, and cold face. HRV analysis was performed in the frequency domain using both autoregressive (AR) and fast Fourier transform algorithms in rest supine condition and during HUTT.

Results: There was a significant increase in systolic blood pressure values in supine rest condition and a trend toward a lower Valsalva ratio in RLS patients with respect to controls. The significant and physiological changes of HRV at HUTT detected in healthy subjects were not found in RLS patients.

Conclusion: RLS patients exhibit a tendency toward hypertension, reduced amplitude of both sympathetic and parasympathetic responses at HUTT, as well as blunted parasympathetic drive to blood pressure changes. These findings, if confirmed by more controlled studies, might support the hypothesis of autonomic nervous system involvement during wakefulness and consequently an enhanced cardiovascular risk in RLS.
\end{abstract}

(C) 2014 Elsevier B.V. All rights reserved.

\section{Introduction}

Restless legs syndrome (RLS) is a common sensorimotor disorder with a prevalence up to $11 \%$ in the general population, and is more frequent in females than in males [1-3]. The diagnosis is made using clinical criteria established by the International Restless Legs Syndrome Study Group (IRLSSG) [4]. The five essential criteria are the following: (i) urgency to move the legs, usually with unpleasant sensations; (ii) appearance of symptoms during inactivity or rest; (iii) relief with movement; (iv) a worsening condition in the evening or at night; (v) such features are not solely accounted for as symptoms primary to another medical or a behavioral condition. RLS remains largely undiagnosed and underestimated. Nevertheless most patients do experience serious clinical consequences with a significant impact on sleep and life quality $[1,2,5]$.

\footnotetext{
* Corresponding author at: Neurology Unit, Department of Systems Medicine, University of Rome "Tor Vergata”, Viale Oxford 81, 00133 Rome, Italy. Tel.: +39 06 20903119; fax: +39 0620903118.

E-mail address: rocchicamilla@gmail.com (C. Rocchi).
}

In the last decade, many authors focused on the potential consequences of RLS on cardio- and cerebrovascular diseases [6,7], sometimes by investigating the autonomic nervous system (ANS), mainly during sleep [8-11].

The hypothesis of ANS impairment in RLS arises from several types of evidence. In fact, epidemiologic studies showed an increased prevalence and incidence of hypertension, cardiovascular, and cerebrovascular diseases in RLS patients with and without periodic limb movements in sleep (PLMS) [12]. However, some authors failed to find any association between RLS and hypertension and/or cardiovascular diseases $[13,14]$. Moreover, changes in sympatho-vagal balance in RLS patients with PLMS were observed during sleep by means of heart rate variability (HRV) spectral analysis [11].

Furthermore, complaints of autonomic system disorders in patients suffering from RLS have been recently observed by means of a subjective scale used in Parkinson disease (SCOPA - autonomic) [15].

On these bases, the present study was carried out in RLS patients during wakefulness, aiming: (i) to study the autonomic control of cardiovascular reflexes under controlled conditions; (ii) to evaluate HRV using both autoregressive analysis (AR) and fast Fourier transform (FFT) models in rest supine condition and during headup tilt test (HUTT). 


\section{Methods}

\subsection{Subjects}

Consecutive adult patients affected by RLS, diagnosed in accordance with the five essential criteria established by the IRLSSG [4], were enrolled.

All patients underwent neurological examination, routine blood tests (including serum iron, transferrin and ferritin, $\mathrm{B}_{12}$ vitamin, and folate), electromyography (EMG) and electroneurography of the lower limbs in order to exclude nervous system diseases and secondary RLS. Diabetes mellitus, hypertension, heart, endocrine, metabolic and renal diseases, and smoking habit were excluded by history taking. Patients with apnea-hypopnea index $>5 / \mathrm{h}$ were excluded by means of polysomnographic (PSG) monitoring performed through an ambulatory dynamic 32-channel system polygraph (Somnoscreen; Somnomedics, Randersacker, Germany). The signal was stored in a flash card utilizing a common average reference and a time constant of $0.3 \mathrm{~s}$. Electrodes were positioned according to the 10-20 International System. The montage consisted of two oculographic channels, three electromyographic channels (mental and anterior tibialis muscles), and eight referential electroencephalographic channels (F4, C4, T4, O2, A2, F3, C3, T3, O1, A1). Respiration was assessed using recordings of oronasal flow, thoracic and abdominal movements (plethysmography), and pulse oximetry. Sleep stage analysis was performed according to the American Academy of Sleep Medicine (AASM) criteria [16]. Hypopneas, apneas, and respiratory effortrelated arousals were scored using the standard AASM criteria [17]. Episodes of PLMS were defined as leg movements with amplitude increase of $8 \mu \mathrm{V}$ above the baseline value, duration of $0.5-10 \mathrm{~s}, \mathrm{a}$ period length between two consecutive movements of 5-90 s, and a minimum of four consecutive movements [18]. Periodic limb movement index (PLMI) was considered pathological if $>15 / \mathrm{h}$. On the basis of PLMI, RLS patients were later divided into two subgroups: RLS patients with PLMS if PLMI $>15 / h\left(\right.$ PLMS $^{+}$) and RLS patients without PLMS if PLMI $<15 / \mathrm{h}\left(\mathrm{PLMS}^{-}\right)$.

Therapies with dopamine agonists were not allowed in the two weeks before the study.

The severity of RLS was assessed by the IRLSSG rating scale (IRLS) [19] commonly used to assess the severity of the disease.

RLS patients were compared with 14 healthy subjects comparable for age and sex, screened by a neurologist with expertise in sleep medicine to exclude sleep disorders and who generally enjoyed good health. Exclusion criteria were: diabetes mellitus, hypertension, heart, endocrine, metabolic and renal diseases, smoking habit, sleep disorder diagnosis (including RLS by using the same criteria set by IRLSSG [4], insomnia, daytime sleepiness, snoring, narcolepsy/ cataplexy sleep apnea), mental illnesses, cognitive problems, and current therapies or previous use of any neuroleptic agent.

Both patients and controls underwent subjective evaluation of sleep quality and daytime somnolence by means of Pittsburgh Sleep Quality Index (PSQI) [20] and Epworth Sleepiness Scale (ESS) [21,22].

All subjects gave their informed consent to the procedures and the study was approved by the local ethics committee.

\subsection{Cardiovascular reflexes}

Both RLS patients and controls were studied in a temperaturecontrolled room $\left(23 \pm 1{ }^{\circ} \mathrm{C}\right)$, at the same time slot (08:00-10:00) since circadian changes affect cardiovascular functions and RLS [23,24].

None of the subjects was under medication known to affect autonomic function and they were asked to abstain from alcohol and caffeine for $\geq 24 \mathrm{~h}$ before the investigations. Continuous noninvasive measurement of systolic and diastolic blood pressure (SBP, DBP) was obtained by an infrared photoplethysmograph (Finometer, Model-1; TNO Biomedical Instrumentation, Amsterdam, The Neth- erlands). Electrocardiography (Click EGC USB 3-12 Leads; ET Medical Devices SpA, Cavareno, Italy) was monitored by standard methods. Respiration rate was also continuously monitored through a nasal thermocouple respiration flow sensor (SleepSense; S.L.P. Inc, Elgin, IL, USA). Autonomic function tests were performed using standard procedures [25]. The tests were performed in the order outlined below, allowing a period of rest aimed at restoring basal blood pressure (BP) and heart rate (HR) values between investigations. The results of each test were automatically obtained by means of LightSNV software (SparkBIO, Spark Srl, Bologna, Italy). All subjects performed the following tests: head-up tilt test (HUTT), Valsalva maneuver, deep breathing, hand grip test, and cold face.

After $30 \mathrm{~min}$ of supine rest, the subject was tilted up at $65^{\circ}$ on HUTT for 10 min. At each minute of HUTT, the changes in SBP, DBP, and HR were calculated with respect to basal values. Pre-HUTT supine values (baseline) for SBP, DBP, and HR were set at 0 , and changes were expressed as $\Delta$ (raw data) from baseline. The Valsalva maneuver was performed by blowing through a mouthpiece attached to a manometer and maintaining a pressure of $40 \mathrm{mmHg}$ for $15 \mathrm{~s}$. We have considered as indices of autonomic activity the ratio between HR in phases II and IV (VR) and the BP variations during phases II and IV. For deep breathing test, the sinus arrhythmia calculated in beats per minute (bpm) was evaluated. The difference between the maximum HR during inspiration and minimum HR during expiration (IE difference) in an individual respiratory cycle was calculated and expressed as the mean of the differences in ten respiratory cycles. At handgrip test, subjects were asked to exert $30 \%$ of maximal voluntary contraction of the dominant hand for 5 min on a dynamometer. BP was measured in the non-exercising arm at rest and at the third minute of the test. In the cold face test, changes in SBP, DBP, and HR were compared to baseline values after $60 \mathrm{~s}$ of synthetic ice $\left(0-1{ }^{\circ} \mathrm{C}\right)$ had been applied to the forehead. A neurologist and a neurophysiopathology technician performed all the autonomic tests, and they did not observe or report any leg movements.

\subsection{Heart rate variability (HRV) analysis}

Heart rate variability analysis was performed on each patient in the frequency domain using dedicated software (Light-SNV software). Stable HR epochs of 5 min duration were chosen in the last 6 min of 30 min supine rest and between the 4th and 9th min of HUTT. Power spectral analysis (PSA) was calculated using both a parametric (AR) and a non-parametric algorithm (FFT). We considered a high-frequency (HF), respiratory-linked component (centred 0.16$0.4 \mathrm{~Hz}$ ), reflecting mostly vagal activity, and a low-frequency (LF) component $(0.04-0.15 \mathrm{~Hz})$, reflecting mostly sympathetic activity. The oscillatory components between $(0-0.03 \mathrm{~Hz})$ were considered to be direct current (DC) noise. The spectral components in normalized units (LFnu, HFnu) were calculated by dividing it by the total power minus the DC component. The LF/HF ratio was used as an index of sympathovagal balance [26].

\subsection{Statistical analysis}

Data were reported as mean \pm standard deviation. The normally distributed data were compared by means of Student's unpaired two-tailed $t$-test. PSA data for HRV, expressed as normalized units not normally distributed, were analyzed using the Mann-Whitney rank-sum test for between-group analysis and Wilcoxon matchedpairs signed rank test for the within-group analysis within the sample. In order to avoid type 1 statistical error, Bonferroni correction was applied when required.

In addition, because of the small sample size and to rule out possible type II error, we calculated effect sizes using Cohen's $d$-value which is defined as the difference between two means divided by 
Table 1

Clinical, demographic data and subjective scales in restless legs syndrome patients and controls.

\begin{tabular}{|c|c|c|c|c|c|c|}
\hline \multirow[t]{2}{*}{ Variable/measure } & \multirow[t]{2}{*}{ RLS patients $(n=12)$} & \multirow[t]{2}{*}{ Controls $(n=14)$} & \multirow[t]{2}{*}{$P$-values } & \multirow[t]{2}{*}{ Cohen's $d$} & \multicolumn{2}{|c|}{$95 \%$ CI for effect size } \\
\hline & & & & & Lower & Upper \\
\hline Age (years) & $58.41 \pm 15.36$ & $51.5 \pm 15.18$ & 0.26 & 0.45 & -0.34 & 1.22 \\
\hline Female:male & $10: 2$ & $11: 3$ & - & & & \\
\hline $\mathrm{BMI}\left(\mathrm{kg} / \mathrm{m}^{2}\right)$ & $24.9 \pm 3.51$ & $24.45 \pm 3.60$ & 0.78 & 0.06 & -0.65 & 0.89 \\
\hline RLS disease duration (years) & $3.46 \pm 2.44$ & - & - & - & - & - \\
\hline IRLS & $26.33 \pm 5.63(26.5)$ & - & - & - & - & - \\
\hline ESS & $6.08 \pm 5.63(4)$ & $1.07 \pm 0.91(1)$ & 0.0002 & 1.24 & 0.41 & 2.1 \\
\hline PSQI & $14.83 \pm 3.24(14.5)$ & $1.57 \pm 1.24(2)$ & 0.00002 & 5.4 & 3.75 & 7.06 \\
\hline
\end{tabular}

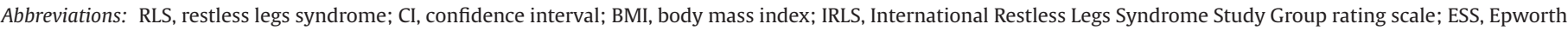
Sleepiness Scale; PSQI, Pittsburgh Sleep Quality Index.

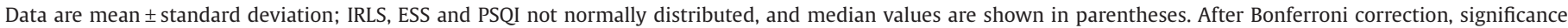
was set at $P<0.025$. Cohen's $d$-value was defined as the difference between two means divided by the pooled standard deviation.

the pooled standard deviation. According to Cohen, 0.2 indicates a small effect, 0.5 a medium effect, and $\geq 0.8$ a large effect.

Statistical analysis was performed using the program Statistics 10.0 program Statsoft Inc. (Tulsa, OK, USA).

\section{Results}

\subsection{Demographic and clinical data}

Twelve patients with RLS [10 females, two males, mean age $58.41 \pm 15.36$ years, body mass index (BMI) $24.9 \pm 3.51$ ], mean disease duration of $4.22 \pm 3.46$ years and 14 healthy controls ( 11 females, 3 males, mean age $51.5 \pm 15.18$ years, BMI $24.45 \pm 3.6$ ) were included in the study.

RLS patients and controls did not significantly differ by age (unpaired $t$-test: $P=0.26)$ and BMI $(P=0.78)$. Of the 12 RLS patients, nine were drug-naive whereas three had been previously treated with pramipexole $0.18 \mathrm{mg} /$ day (duration of treatment $1-4$ weeks) but discontinued such drug therapy due to poor adherence or side-effects at least two weeks before starting the study. Polysomnographic evaluation showed PLMI $>15 /$ h in six RLS patients (PLMI $38.05 \pm 17.35$ ), whereas six patients had PLMI $<15 / \mathrm{h}$ (PLMI $8 \pm 3.86$ ). PLM during relaxed wakefulness (PLMW) index was $1.5 \pm 2.1 / \mathrm{h}$ (range $0-7.1 / \mathrm{h}$ ). At IRLS, two patients had very severe degree of disease (score 31-40), eight had severe degree (score 2130 ) and the remaining two had moderate degree (score 11-20). None of our patients had mild RLS (score 1-10). All RLS patients reported sleep complaints as measured by means of the PSQI (PSQI $>5$ ). The PSQI global score was significantly increased in comparison with controls $(P=0.0002)$. ESS score was significantly higher in RLS with respect to controls $(P=0.00002)$. Three out of 12 pa- tients had an ESS $>10$. Demographic, clinical data and subjective scales of patients and controls are shown in Table 1.

\subsection{Cardiovascular reflexes}

All subjects properly performed all cardiovascular tests. In supine rest condition the baseline values of SBP were significantly increased in RLS patients compared with controls $(P=0.005)$, whereas the basal values of DBP and HR were similar in the two groups. After 10 min of HUTT, $\Delta$ HR was significantly higher in the control group compared to RLS $(P=0.003)$ (Table 2). At Valsalva maneuver patients exhibited a non-significant trend toward lower VR $(P=0.02)$ than controls. Cardiovascular responses to deep breathing, isometric handgrip, cold face were normal and similar in RLS patients and control (Table 3). No statistical differences between RLS patients with and without PLMS were detected (Supplementary Tables S1 and S2).

\subsection{HRV analysis}

Spectral analysis of HRV showed no significant differences between RLS and controls in supine rest condition and during HUTT, both using AR and FFT algorithm (Table 4). The within-group analysis on LFnu and HFnu components at rest and during HUTT showed a significant increase in LFnu component $(A R, P=0.01)$ and a significant reduction in HFnu component (AR, $P=0.01$; FFT, $P=0.006$ ) and accordingly a significant increase in the LF/HF ratio (FFT, $P=0.002$ ) during HUTT with respect to supine rest condition in controls. No significant changes in LFnu and HFnu components during HUTT were detected in RLS patients (Table 5).

Table 2

Cardiovascular responses at supine rest and at 10 th $\mathrm{min}$ of head-up tilt test in restless legs syndrome patients and controls.

\begin{tabular}{|c|c|c|c|c|c|c|}
\hline \multirow[t]{2}{*}{ Variables } & \multirow[t]{2}{*}{ RLS patients $(n=12)$} & \multirow[t]{2}{*}{ Controls $(n=14)$} & \multirow[t]{2}{*}{$P$-values } & \multirow[t]{2}{*}{ Cohen's $d$} & \multicolumn{2}{|c|}{$95 \% \mathrm{CI}$ for effect size } \\
\hline & & & & & Lower & Upper \\
\hline \multicolumn{7}{|l|}{ Supine rest } \\
\hline $\mathrm{SBP}(\mathrm{mmHg})$ & $135.25 \pm 14.42$ & $120.07 \pm 14.15$ & 0.005 & 1.06 & 0.21 & 1.85 \\
\hline $\mathrm{DBP}(\mathrm{mmHg})$ & $64.25 \pm 13.20$ & $64.5 \pm 10.38$ & 1.0 & -0.02 & -0.79 & 0.75 \\
\hline $\mathrm{HR}(\mathrm{bpm})$ & $67.67 \pm 11.54$ & $69.64 \pm 9.29$ & 0.4 & -0.18 & -0.96 & 0.59 \\
\hline \multicolumn{7}{|c|}{ Differences after $10 \mathrm{~min}$ tilt } \\
\hline$\triangle \mathrm{SBP}(\mathrm{mmHg})$ & $7 \pm 17.34$ & $-1.37 \pm 13.16$ & 0.3 & 0.54 & -0.25 & 1.32 \\
\hline$\Delta \mathrm{DBP}(\mathrm{mmHg})$ & $7.09 \pm 12.80$ & $2.38 \pm 5.88$ & 0.3 & 0.47 & -0.31 & 1.25 \\
\hline$\Delta \mathrm{HR}(\mathrm{bpm})$ & $6.67 \pm 3.72$ & $15.75 \pm 7.67$ & 0.003 & -1.5 & -2.29 & -0.56 \\
\hline
\end{tabular}

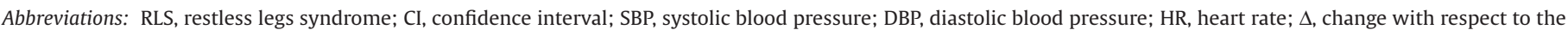
basal value.

Supine rest: values of supine rest assessed by averaging all blood pressure and HR values from the last 5 min before head-up tilt test (HUTT). Differences after 10 min tilt: changes in SBP and DBP and in HR obtained by calculating the mean value of the last of 10 min of HUTT.

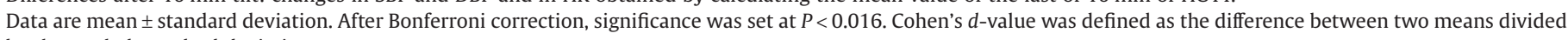
by the pooled standard deviation. 
Table 3

Cardiovascular responses to Valsalva maneuver, deep breathing, cold face, and handgrip in restless legs syndrome patients versus controls.

\begin{tabular}{|c|c|c|c|c|c|c|}
\hline \multirow[t]{2}{*}{ Patient variables } & \multicolumn{2}{|l|}{ Valsalva } & \multirow{2}{*}{$\frac{\text { Deep breathing }}{\mathrm{I}-\mathrm{E}}$} & \multicolumn{2}{|l|}{ Cold face } & \multirow{2}{*}{$\frac{\text { Isometric handgrip }}{\Delta \mathrm{DBP}(\mathrm{mmHg})}$} \\
\hline & VR & $\mathrm{OV}(\mathrm{mmHg})$ & & $\triangle \mathrm{DBP}(\mathrm{mmHg})$ & $\Delta \mathrm{HR}(\mathrm{bpm})$ & \\
\hline RLS patients $(n=12)$ & $1.49 \pm 0.22$ & $37.54 \pm 18.25$ & $17.25 \pm 13.65$ & $23.59 \pm 14.87$ & $-6.41 \pm 4.83$ & $15.91 \pm 5.80$ \\
\hline Controls $(n=14)$ & $1.76 \pm 0.28$ & $45.59 \pm 17.68$ & $17.75 \pm 7.10$ & $27.75 \pm 4.92$ & $-8.5 \pm 9.54$ & $20.2 \pm 10.64$ \\
\hline$P$-value & 0.02 & 0.3 & 0.3 & 0.3 & 0.6 & 0.4 \\
\hline Cohen's $d$ & -1.07 & -0.44 & -0.04 & -0.37 & 0.27 & -0.48 \\
\hline \multicolumn{7}{|l|}{$95 \% \mathrm{CI}$} \\
\hline Lower & -1.85 & -1.21 & -0.82 & -1.15 & 0.401 & -1.256 \\
\hline Upper & -0.21 & 0.35 & 0.73 & -0.51 & 1.04 & 0.308 \\
\hline
\end{tabular}

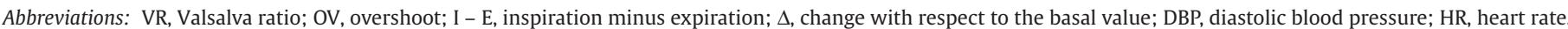

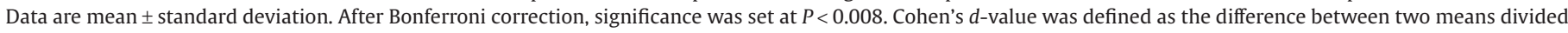
by the pooled standard deviation. $95 \% \mathrm{CI}$, confidence interval for effect size.

\section{Discussion}

The present study explored ANS in RLS patients, focusing on wakefulness.

There was a significant increase in baseline SBP in the rest supine condition compared to controls. Although these values are not suggestive of hypertension, the mean baseline SBP $(135 \mathrm{mmHg})$ satisfies the criteria of systolic pre-hypertension [27] that is known to increase the risk of cardiovascular diseases [28]. Our finding is in agreement with epidemiological studies [12] and supports the hypothesis of a tendency toward hypertension in RLS.
The link between RLS and hypertension may rest in the neurological circuits supposed to be involved in the pathophysiology of this disorder [29]. Clemens et al. suggested that clinical aspects of RLS and its association with cardiovascular diseases, including hypertension, lie in the dopaminergic neurons of the hypothalamic A11 nucleus [29]. The dopaminergic inhibitory descending pathways project in all regions of the spinal cord and preferentially to the dorsal and ventral horns and to the intermediate-lateral nucleus (IML) of the spinal gray matter that represents the final common pathway of the sympathetic system. According to this model, the loss of dopaminergic input to the spinal cord leads to the

Table 4

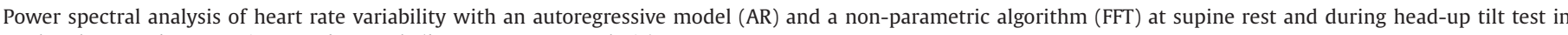
restless legs syndrome patients and controls (between-group analysis).

\begin{tabular}{|c|c|c|c|c|c|c|c|c|}
\hline \multicolumn{3}{|c|}{ Model/algorithm } & \multirow[t]{2}{*}{$\operatorname{RLS}(n=12)$} & \multirow[t]{2}{*}{ Controls $(n=14)$} & \multirow[t]{2}{*}{$P$-value } & \multirow[t]{2}{*}{ Cohen's $d$} & \multicolumn{2}{|l|}{$95 \% \mathrm{CI}$} \\
\hline & & & & & & & Lower & Upper \\
\hline \multirow[t]{6}{*}{$\mathrm{AR}$} & \multirow[t]{3}{*}{ Rest supine } & LFnu & $53.29 \pm 23.53$ & $51.40 \pm 19.62$ & 0.64 & 0.08 & -0.69 & 0.86 \\
\hline & & HFnu & $45.96 \pm 23.15$ & $48.60 \pm 19.62$ & 0.68 & -0.12 & -0.89 & 0.65 \\
\hline & & $\mathrm{LF} / \mathrm{HF}$ & $1.89 \pm 1.90$ & $1.60 \pm 1.63$ & 0.70 & 0.16 & -0.61 & 0.93 \\
\hline & \multirow[t]{3}{*}{ Tilt } & LFnu & $60.10 \pm 19.07$ & $68.15 \pm 13.95$ & 0.33 & -0.48 & -1.25 & 0.31 \\
\hline & & HFnu & $39.90 \pm 19.07$ & $31.85 \pm 13.95$ & 0.33 & 0.48 & -0.31 & 1.25 \\
\hline & & $\mathrm{LF} / \mathrm{HF}$ & $2.33 \pm 2.05$ & $2.70 \pm 1.46$ & 0.33 & -0.2 & -0.98 & 0.57 \\
\hline \multirow[t]{6}{*}{ FFT } & \multirow[t]{3}{*}{ Rest supine } & LFnu & $57.10 \pm 24.69$ & $52.30 \pm 19.77$ & 0.44 & 0.21 & -0.56 & 0.98 \\
\hline & & HFnu & $42.90 \pm 24.69$ & $47.70 \pm 19.77$ & 0.44 & -0.21 & -0.98 & 0.56 \\
\hline & & $\mathrm{LF} / \mathrm{HF}$ & $2.45 \pm 2.62$ & $1.79 \pm 2.06$ & 0.44 & 0.28 & -0.50 & 1.05 \\
\hline & \multirow[t]{3}{*}{ Tilt } & LFnu & $65.62 \pm 18.32$ & $66.33 \pm 22.31$ & 0.76 & -0.04 & -0.80 & 0.74 \\
\hline & & HFnu & $34.37 \pm 18.31$ & $32.83 \pm 19.91$ & 0.76 & 0.08 & -0.69 & 0.85 \\
\hline & & $\mathrm{LF} / \mathrm{HF}$ & $3.02 \pm 2.45$ & $3.40 \pm 2.08$ & 0.44 & -0.16 & -0.94 & 0.61 \\
\hline
\end{tabular}

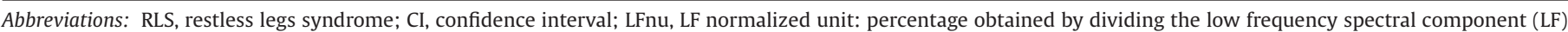

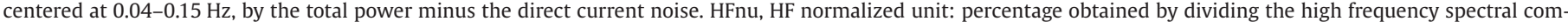

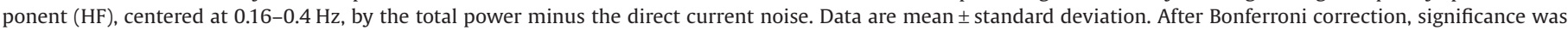
set at $P<0.016$. Cohen's $d$-value was defined as the difference between two means divided by the pooled standard deviation.

Table 5

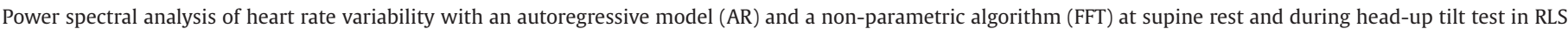
patients and controls (within-group analysis).

\begin{tabular}{|c|c|c|c|c|c|c|c|c|c|c|c|c|}
\hline \multirow[t]{3}{*}{ Model/algorithm } & \multicolumn{6}{|c|}{ Controls $(n=14)$} & \multicolumn{6}{|l|}{$\operatorname{RLS}(n=12)$} \\
\hline & \multirow[t]{2}{*}{ Rest supine } & \multirow[t]{2}{*}{ Tilt } & \multirow[t]{2}{*}{$P$-value } & \multirow[t]{2}{*}{ Cohen's $d$} & \multicolumn{2}{|l|}{$95 \% \mathrm{CI}$} & \multirow{2}{*}{ Rest supine } & \multirow[t]{2}{*}{ Tilt } & \multirow{2}{*}{$P$-value } & \multirow[t]{2}{*}{ Cohen's $d$} & \multicolumn{2}{|l|}{$95 \% \mathrm{CI}$} \\
\hline & & & & & Lower & Upper & & & & & Lower & Upper \\
\hline \multicolumn{13}{|l|}{ AR } \\
\hline LFnu & $51.40 \pm 19.62$ & $68.15 \pm 13.95$ & 0.013 & -0.98 & -1.74 & -0.17 & $53.29 \pm 23.53$ & $60.10 \pm 19.07$ & 0.08 & -0.31 & -1.11 & 0.50 \\
\hline HFnu & $48.60 \pm 19.62$ & $31.85 \pm 13.95$ & 0.013 & 0.98 & -0.17 & -1.74 & $45.96 \pm 23.15$ & $39.90 \pm 19.07$ & 0.08 & 0.28 & -0.53 & 1.08 \\
\hline $\mathrm{LF} / \mathrm{HF}$ & $1.60 \pm 1.63$ & $2.70 \pm 1.46$ & 0.04 & -0.71 & -1.45 & 0.07 & $1.89 \pm 1.90$ & $2.33 \pm 2.05$ & 0.08 & -0.22 & -1.02 & 0.59 \\
\hline \multicolumn{13}{|l|}{ FFT } \\
\hline LFnu & $52.30 \pm 19.77$ & $66.33 \pm 22.31$ & 0.02 & -0.66 & -1.41 & 0.11 & $57.10 \pm 24.69$ & $65.62 \pm 18.32$ & 0.5 & -0.39 & -1.19 & 0.43 \\
\hline HFnu & $47.70 \pm 19.77$ & $32.83 \pm 19.91$ & 0.006 & 1.03 & -0.04 & 1.49 & $42.90 \pm 24.69$ & $34.37 \pm 18.31$ & 0.5 & 0.39 & -0.43 & 1.19 \\
\hline $\mathrm{LF} / \mathrm{HF}$ & $1.79 \pm 2.06$ & $3.40 \pm 2.08$ & 0.002 & -0.77 & -1.52 & 0.01 & $2.45 \pm 2.62$ & $3.02 \pm 2.45$ & 0.6 & -0.22 & -1.02 & 0.59 \\
\hline
\end{tabular}

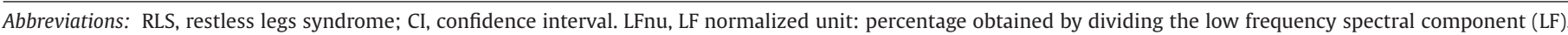

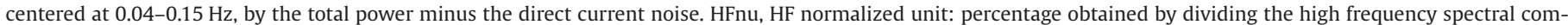

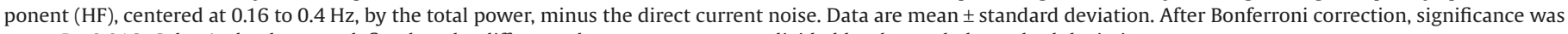
set at $P<0.016$. Cohen's $d$-value was defined as the difference between two means divided by the pooled standard deviation. 
disinhibition of the somatosensory pathways, explaining the typical and unpleasant sensation in the limbs. Moreover, the disinhibition of IML leads to an increase in sympathetic output that might explain the alteration of ANS observed by some authors [11,29].

In addition, there is wide evidence that the dopaminergic system dysfunction induces hypertension [30-32], as supported by experimental studies in dopamine D3 knockout mice that has been proposed as a potential animal model for RLS [33].

Our study excluded abnormal cardiovascular responses to HUTT, cold face, deep breathing, and isometric handgrip tests; however, the patients exhibited a non-significant trend toward a lower Valsalva ratio than controls. This result, though, lost its statistical significance after Bonferroni correction. The VR is an index of parasympathetic function representing the vagal component of the baroreflex [34]. Since parasympathetic response at Valsalva maneuver was slightly reduced in our sample, we can speculate that the predisposition to hypertension in RLS may be favored by a blunted parasympathetic response to changes in blood pressure. In support of this hypothesis, it has been documented that an attenuation of cardiovagal function is associated with increased risk of pre-hypertension in young adults [35].

Spectral analysis of HRV did not show significant differences in our sample between RLS and controls, neither in supine rest condition nor during HUTT. Our result matches previous studies that analyzed HRV during sleep sequences without PLMS in subjects with RLS [11], confirming that the autonomic sympathovagal balance seems unaffected at rest condition.

However, whereas the HRV analysis shows a statistically significant variation in most HRV components during HUTT compared to the supine position in controls, such variation does not occur in RLS patients using both parametric (AR) and non-parametric (FFT) algorithms. The lack of variability at HUTT was observed in patients with narcolepsy in which an exaggerated sympathetic nerve activity at rest was postulated [36]. Conversely, the sympathovagal balance in our group was unimpaired at rest, as already described in previous papers [11], but was altered in response to HUTT. The failure of expected change in PSA at orthostatic stress could explain symptoms of orthostatic intolerance (i.e. dizziness) subjectively reported by RLS patients during the transition to the orthostatic position [15].

In addition, there is evidence that acute sleep deprivation reduces the amplitude of both sympathetic and parasympathetic responses at HUTT in healthy subjects [37], similar to what has been observed in our sample. Therefore we cannot rule out that sleep disturbances associated with RLS (insomnia, poor sleep efficiency), rather than the disease itself, are responsible for lower reactivity of the autonomic system during orthostatic stress.

Cardiovascular responses do not differ between $\mathrm{PLMS}^{+}$versus PLMS $^{-}$patients but the small sample size, with only six subjects in each group, does not allow us to interpret these results statistically. We believe that it would be interesting to delve into this topic since recent studies observed that cardiovascular changes are more pronounced in RLS subjects compared to healthy subjects with PLMS [38], and that HRV analysis during sleep does not show any statistical differences in basal cardiac autonomic tone between subjects with PLMS and controls [39].

Some limitations of our study have to be considered. First, the sample size was small and there was no objective measure of sleep in control subjects. Furthermore, the possible appearance of leg movements during the cardiovascular test was not recorded by means of electromyographic channels in both RLS patients and controls. Finally, three patients were not drug-naive.

Despite these limitations, our findings suggest an involvement of ANS during wakefulness that may explain the enhanced cardiovascular risk in RLS. Additional and larger studies are needed to further explore this topic.

\section{Funding}

None.

\section{Conflict of interest}

The ICMJE Uniform Disclosure Form for Potential Conflicts of Interest associated with this article can be viewed by clicking on the following link: http://dx.doi.org/10.1016/j.sleep.2014.06.022.

\section{Appendix: Supplementary data}

Supplementary data to this article can be found online at doi:10.1016/j.sleep.2014.06.022.

\section{References}

[1] Hogl B, Kiechl S, Willeit J, Saletu M, Frauscher B, Seppi K, et al. Restless legs syndrome: a community-based study of prevalence, severity, and risk factors. Neurology 2005;64:1920-4.

[2] Winkelman JW, Finn L, Young T. Prevalence and correlates of restless legs syndrome symptoms in the Wisconsin sleep cohort. Sleep Med 2006;7:545-52.

[3] Allen RP, Bharmal M, Calloway M. Prevalence and disease burden of primary restless legs syndrome: results of a general population survey in the United States. Mov Disord 2011;26:114-20.

[4] International Restless Legs Syndrome Study Group. 2011 revised IRLSSG diagnostic criteria for RLS, <http://irlssg.org/diagnostic-criteria/>; 2011 [accessed 13.06.02].

[5] Allen RP, Walters AS, Montplaisir J, Hening W, Myers A, Bell TJ, et al. Restless legs syndrome prevalence and impact: REST general population study. Arch Intern Med 2005;165:1286-92.

[6] Winkelman JW, Shahar E, Sharief I, Gottlieb DJ. Association of restless legs syndrome and cardiovascular disease in the Sleep Heart Health Study. Neurology 2008;70:35-42.

[7] Walters AS, Rye DB. Review of the relationship of restless legs syndrome and periodic limb movements in sleep to hypertension, heart disease, and stroke. Sleep 2009;32:589-97.

[8] Gosselin N, Lanfranchi P, Michaud M, Fantini L, Carrier J, Lavigne G, et al. Age and gender effects on heart rate activation associated with periodic leg movements in patients with restless legs syndrome. Clin Neurophysiol 2003; 114:2188-95.

[9] Ferri R, Zucconi M, Rundo F, Spruyt K, Manconi M, Ferini-Strambi L. Heart rate and spectral EEG changes accompanying periodic and non-periodic leg movements during sleep. Clin Neurophysiol 2007;118:438-48.

[10] Pennestri MH, Montplaisir J, Colombo R, Lavigne G, Lanfranchi PA. Nocturnal blood pressure changes in patients with restless legs syndrome. Neurology 2007;68:1213-18

[11] Manconi M, Ferri R, Zucconi M, Clemens S, Rundo F, Oldani A, et al. Effects of acute dopamine-agonist treatment in restless legs syndrome on heart rate variability during sleep. Sleep Med 2011;12:47-55.

[12] Ferini-Strambi L, Walters AS, Sica D. The relationship among restless legs syndrome (Willis-Ekbom disease), hypertension, cardiovascular disease, and cerebrovascular disease. J Neurol 2014;261:1051-68.

[13] Winter AC, Schürks M, Glynn RJ, Buring JE, Gaziano JM, Berger K, et al. Restless legs syndrome and risk of incident cardiovascular disease in women and men: prospective cohort study. BMJ Open 2012;2:e000866

[14] Giannini G1, Zanigni S, Melotti R, Gögele M, Provini F, Facheris MF, et al. Association between restless legs syndrome and hypertension: a preliminary population-based study in South Tyrol, Italy. Eur J Neurol 2014;21:72-8.

[15] Shneyder N, Adler CH, Hentz JG, Shill H, Caviness JN, Sabbagh MN, et al. Autonomic complaints in patients with restless legs syndrome. Sleep Med 2013;14:1413-16.

[16] Iber C, Ancoli-Israel S, Chesson A, Quan S, for the American Academy of Sleep Medicine. The AASM manual for the scoring of sleep and associated events: rules, terminology and technical specifications. 1st ed. Westchester, IL: American Academy of Sleep Medicine; 2007.

[17] American Academy of Sleep Medicine. ICSD-2 - International Classification of Sleep Disorders. Diagnostic and coding manual. 2nd ed. American Academy of Sleep Medicine; 2005.

[18] Zucconi M, Ferri R, Allen R, Baier PC, Bruni O, Chokroverty S, et al. The official World Association of Sleep Medicine (WASM) standards for recording and scoring periodic leg movements in sleep (PLMS) and wakefulness (PLMW) developed in collaboration with a task force from the international restless legs syndrome study group (IRLSSG). Sleep Med 2006;7:175-83.

[19] Walters AS, LeBrocq C, Dhar A, Hening W, Rosen R, Allen RP, et al. Validation of the International Restless Legs Syndrome Study Group rating scale for restless legs syndrome. Sleep Med 2003;4:121-32.

[20] Buysse DJ, Reynolds CF, Monk TH, Berman SR, Kupfer DJ. The Pittsburgh Sleep Quality Index (PSQI): a new instrument for psychiatric research and practice. Psychiatry Res 1989;28(2):193-213. 
[21] Johns MW. A new method for measuring daytime sleepiness: the Epworth Sleepiness Scale. Sleep 1991;14:540-5.

[22] Vignatelli L, Plazzi G, Barbato A, Ferini-Strambi L, Manni R, Pompei F, et al. Italian version of the Epworth Sleepiness Scale: external validity. Neurol Sci 2003;23:295-300.

[23] Morris CJ, Yang JN, Scheer FA. The impact of the circadian timing system on cardiovascular and metabolic function. Prog Brain Res 2012;199:337-58.

[24] Hening WA, Walters AS, Wagner M, Rosen R, Chen V, Kim S, et al. Circadian rhythm of motor restlessness and sensory symptoms in the idiopathic restless legs syndrome. Sleep 1999;22:901-12.

[25] Mathias CJ, Bannister R. Investigation of autonomic disorders. In: Mathias CJ, Bannister R, editors. Autonomic failure: a text book of clinical disorders of the autonomic nervous system. 4th ed. Oxford: Oxford University Press; 1999. p. 169-95.

[26] Task Force of the European Society of Cardiology and the North American Society of Pacing and Electrophysiology. Heart rate variability: standards of measurement, physiological interpretation and clinical use. Circulation 1996;93:1043-65.

[27] Chobanian AV, Bakris GL, Black HR, Cushman WC, Green LA, Izzo JL Jr, et al. Seventh report of the Joint National Committee on Prevention, Detection, Evaluation, and Treatment of High Blood Pressure. Hypertension 2003; 42:1206-52.

[28] Qureshi AI, Suri MF, Kirmani JF, Divani AA, Mohammad Y. Is prehypertension a risk factor for cardiovascular diseases? Stroke 2005;36:1859-63.

[29] Clemens S, Rye D, Hochman S. Restless legs syndrome: revisiting the dopamine hypothesis from the spinal cord perspective. Neurology 2006;67:125-30.

[30] Jose PA, Eisner GM, Felder RA. Renal dopamine receptors in health and hypertension. Pharmacol Ther 1998;80:149-82.
[31] Felder RA, Seikaly MG, Cody P, Eisner GM, Jose PA. Attenuated renal response to dopaminergic drugs in spontaneously hypertensive rats. Hypertension 1990;15:560-9.

[32] Kunimi M, Seki G, Hara C, Taniguchi S, Uwatoko S, Goto A, et al. Dopamine inhibits renal $\mathrm{Na}^{+}$. Kidney Int 2000;57:534-43.

[33] Clemens S, Hochman S. Conversion of the modulatory actions of dopamine on spinal reflexes from depression to facilitation in D3 receptor knock-out mice. J Neurosci 2004;24:11337-45.

[34] Low PA, Tomalia VA, Park KJ. Autonomic function tests: some clinical applications. J Clin Neurol 2013;9:1-8.

[35] Thiyagarajan R, Pal P, Pal GK, Subramanian SK, Bobby Z, Das AK, et al. Cardiovagal modulation, oxidative stress, and cardiovascular risk factors in prehypertensive subjects: cross-sectional study. Am J Hypertens 2013;26:850-7.

[36] Grimaldi D, Pierangeli G, Barletta G, Terlizzi R, Plazzi G, Cevoli S, et al. Spectral analysis of heart rate variability reveals an enhanced sympathetic activity in narcolepsy with cataplexy. Clin Neurophysiol 2010;121:1142-7.

[37] Tobaldini E, Cogliati C, Fiorelli EM, Nunziata V, Wu MA, Prado M, et al. One night on-call: sleep deprivation affects cardiac autonomic control and inflammation in physicians. Eur J Intern Med 2013;24:664-70.

[38] Pennestri MH, Montplaisir J, Fradette L, Lavigne G, Colombo R, Lanfranchi PA. Blood pressure changes associated with periodic leg movements during sleep in healthy subjects. Sleep Med 2013;14:555-61.

[39] Palma JA, Alegre M, Valencia M, Artieda J, Iriarte J, Urrestarazu E. Basal cardiac autonomic tone is normal in patients with periodic leg movements during sleep. J Neural Transm 2014;121:385-90. 